\title{
PRODUKTIVITAS TANAMAN KAKAO BERDASARKAN UMUR DI TAMAN TEKNOLOGI PERTANIAN NGLANGGERAN
}

\author{
Wahyu Adhi Saputro ${ }^{1}$, Octaviana Helbawanti ${ }^{2}$ \\ ${ }^{1}$ Program Studi Agribisnis, Fakultas Sains dan Teknologi, Universtas Duta Bangsa Surakarta, \\ ${ }^{2}$ Program Studi Agribisnis, Fakultas Pertanian, Universtas Siliwangi, \\ ${ }^{1}$ email: wahyuadhi@udb.ac.id \\ 2 email: octaviana@unsil.ac.id
}

\begin{abstract}
ABSTRAK
Produksi kakao dunia salah satunya dipenuhi oleh produksi kakao yang berasal dari Indonesia. Daerah yang membudidayakan kakao dengan integrasi kambing etawa di Taman Teknologi Pertanian Nglanggeran Kecamatan Patuk Gunungkidul. Populasi dalam penelitian ini adalah semua petani kakao yang ada di Taman Teknologi Pertanian Nglanggeran sementara sampel merupakan petani yang memiliki pohon kakao usia produktif kurang dari lima belas tahun dan petani kakao yang memiliki pohon kakao usia non produktif lebih dari lima belas tahun menggunakan simple random sampling. Analisis data yang digunakan adalah uji-t test paired two sample. Berdasarkan hasil penelitian didapatkan hasil bahwa kakao umun produktif kurang dari lima belas tahun memiliki produktivitas yang lebih baik jika dibandingkan kakao yang memasuki umur tidak produktif lebih dari sama dengan lima belas tahun. Rerata produktivitas kakao umur produktif sebesar 744,20 Kg/Ha sementara rerata produktivitas kakao umur tidak produktif sebesar $588,41 \mathrm{Kg} / \mathrm{ha}$.
\end{abstract}

Kata Kunci : Produksi, kakao, Produktivitas

\begin{abstract}
One of the world's cocoa production is fulfilled by the production of cocoa originating from Indonesia. The area that cultivates cocoa with the integration of etawa goats in Nglanggeran Agricultural Technology Park, Patuk Gunungkidul District. The population in this study were all cocoa farmers in Nglanggeran Agricultural Technology Park while the sample was farmers who had productive age less than fifteen years and cocoa farmers who had non productive age cocoa trees for more than fifteen years using simple random sampling. Analysis of the data used is paired two sample t-test. Based on the results of the study it was found that productive cocoa less than fifteen years had better productivity when compared to cocoa that entered non-productive age by more than fifteen years. The average productivity of productive age cocoa is $744.20 \mathrm{~kg} / \mathrm{ha}$ while the average productivity of unproductive cocoa is $588.41 \mathrm{~kg} / \mathrm{ha}$.
\end{abstract}

Keywords : Production, Cocoa, Productivity 


\section{PENDAHULUAN}

Produksi kakao dunia sekitar 95\% dipenuhi dari perkebunan dengan pengelola petani kecil. Indonesia adalah salah satu negara yang memiliki produksi kakao yang cukup paik. Sebanyak 1,6 juta keluarga petani di Indonesia memiliki sumber pendapatan utama dari hasil budidaya tanaman kakao (Saleh dan Jayanti, 2017). Potensi pengembangan kakao di Indonesia sebenarnya sangat menjanjikan apabila sejak pengelolaan baik awal tanam, budidaya, pasca panen, industry hingga proses distribusi dan pemasaran dikelola dengan baik. Pengembangan kakao di Indonesia sebagian besar dikelola dalam bentuk perkebunan rakyat. Tahun 2009, luas lahan kakao yang tercatat $92,6 \%$ dikelola oleh rakyat dan selebihnya $3,3 \%$ perkebunan besar negara serta $4,1 \%$ perkebunan besar swasta.

Budidaya kakao yang tradisional masih dimiliki oleh banyak perkebunan rakyat di Indonesia. Umumnya budidaya kakao tersebut hanya mengandalkan tenaga kerja dalam keluarga dalam pengelolaan tanaman kakao. Hal tersebut juga diiringi minimnya inovasi dan teknologi pada budidaya kakao sehingga banyak sekali pohon kakao yang dibudidayakan kurang dirawat dengan baik. Jumlah petani kakao perkebunan mengalami peningkatan akan tetapi peningkatan tersebut tidak diiringi dengan peningkatan produksi dan produktivitas kakao (Alkamalia dkk., 2017)

Terdapat beberapa hambatan dalam pengembangan budidaya kakao terutama masalah hama dan penyakit disertai sumber daya manusia yang kurang baik. Petani kakao hanya bermodalkan pengetahuan bercocok tanam kakao turun temurun dari orang tuanya. Sebenarnya terdapat peluang bagi para investor jika menilik sebagian besar perkebunana kakao di Indonesia adalah perkebunan rakyat. Hal tersebut untuk mengembangkan usaha kakao dan meraih nilai tambah yang lebih besar dari agribisnis kakao. Rata-rata luas lahan, produksi dan produktivitas kakao di Indonesia sudah cukup baik pada tahun 2014 hingga tahun 2016. Rerata produksi tahun 2014 hingga tahun 2016 berkisar pada angka $716.695,33$ ton dengan produktivitas sebesar 799,67 kg/Ha. D.I. Yogyakarta merupakan salah satu daerah penghasil Kakao. Sampai dengan akhir tahun 2016, Yogyakarta memiliki potensi lahan kakao seluas 5.088 Ha dengan produksi 1.039 Ton, yang terletak di 2 Kabupaten yaitu Kabupaten Kulon Progo, Kabupaten Gunungkidul (Apriliawan dkk., 2018). Hasil panen kakao tidaklah stabil dan banyak faktor yang mempengaruhinya. Pendapatan petani sangat bergantung pada produksi kakao yang dihasilkan semakin tinggi produksi kakao maka semakin tinggi pula kenaikan pendapatan petani begitu juga sebaliknya (Saputro dan Sariningsih, 2020). Faktor yang mempengaruhi produksi kakao di Desa Nglanggeran adalah luas lahan, pestisida dan jumlah pohon kakao yang bereproduksi (Saputro dan Fidayani, 2020).

Sub sektor perkebunan memiliki banyak komoditi yang di dalamnya terkandung nilai ekonomis yang tinggi. Pemasok devisa negara salah satunya bersumber dari subsektor perkebunan. Pemerintah telah melakukan beberapa upaya dalam meningkatkan produksi 
komoditi perkebunan. Cara pertama yang dilakukan adalah dengan intensifikasi. Intensifikasi merupakan upaya mengoptimalkan lahan yang sudah ada agar hasil pertanian meningkat. Cara yang kedua dengan ekstensifikasi yaitu perluasan lahan. Cara ketiga yaitu diversifikasi dengan melakukan penganekaragaman komoditi pertanian. Cara yang keempat dengan cara rehabilitasi dengan memperbaharui cara budidaya maupun mengganti tanaman yang tidak produktif lagi (Ikhsan dkk., 2016). Banyak petani yang berbudidaya kakao lebih dari 30 tahun dengan rerata pengalaman dalam bidang pertanian kakao sekitar 25,70 tahun (Ebewore et al., 2013). Indikasi tersebut berarti bahwa petani kakao bukanlah petani kakao yang baru dengan katalain tidaklah minim pengetahuan dalam budidaya kakao (Oyediran et al., 2014).

Penelitian di bidang sub sektor perkebunan merupakan hal penting karena komoditi kakao mempunyai peran penting bagi perekonomian nasional. Akan tetapi dibalik hal tersebut masih ada beberapa masalah yang membuat perkebunan kakao di Indonesia terhambat diikuti masalah pengembangan agribisnis kakao yang masih sulit tumbuh. Permasalahan seperti produktivitas kakao yang masih rendah dimungkinkan karena umur kakao yang sudah tidak dalam masa produktif. Berdasarkan hal tersebut penelitian ini bertujuan untuk mengetahui produktivitas kakao pada usia tanaman 15 tahun dan lebih dari sama dengan 15 tahun.

\section{METODE PENELITIAN}

Lokasi penelitian berada di Desa Nglanggeran yang termasuk ke dalam Taman Teknologi Pertanian tepatnya di
Kecamatan Patuk Kabupaten Gunungkidul Yogyakarta. Pemilihan lokasi ini bersifat secara sengaja dengan metode purposive. Teknik penentuan lokasi ini menggunakan pertimbangan yang ditentukan secara matang (Sugiyono, 2013). Hal tersebut didasari bahwa lokasi tersebut sebagian besar warganya bekerja sebagai petani kakao dan hasil kakao tersebut disetorkan di Taman Teknologi Pertanian. Selain itu lokasi tersebut juga memberikan adopsi dan inovasi dalam budidaya kakao baik on farm dan off farm serta integrasi budidaya kakao dengan hewan ternak berupa kambing etawa. Populasi dalam penelitian ini adalah seluruh petani kakao yang ada di Desa Nglanggeran dengan sampel petani berjumlah 30 petani yang memiliki kakao dengan rentang umur kurang dari 15 tahun dan kakao dengan umur lebih dari sama dengan 15 tahun. Data primer diperoleh dari wawancara langsung menggunakan kuesioner ke petani kakao sementara data sekunder diperoleh dari instansi terkait dan jurnal-jurnal yang relevan.

Perbedaan produktivitas antar umur kakao dapat diketahui dengan metode analisis perbedaan produktivitas kakao umur 15 tahun dan dibandingkan dengan kakao dengan umur yang sama atau lebih dari 15 tahun. Kategori dasar penelitian menggunakan kakao umur 15 tahun dikarenakan tanaman kakao produktivitasnya akan mengalami penurunan setelah umur 15 tahun hingga tahun ke 20 setelah tanam. Pada saat umur kakao berada pada rentang umur 15 hingga 20 tahun produktivitasnya sama dengan setengah dari produktivitas potensialnya (Zainudin dan Baon, 2004). Produktivitas tanaman kakao dapat dihitung dengan menggunakan rumus berikut: 
Produktivitas $=\frac{\text { jumlah output kakao }(\mathrm{kg})}{\text { Luas lahan }(\mathrm{ha})}$

Nilai produktivitas kakao nantinya dihitung reratanya masing masing umur baik kakao berumur kurang dari 15 tahun maupun kakao berumur lebih dari sama dengan 15 tahun. Uji statistik yang digunakan untuk membandingkan produktivitas tanaman kakao adalah dependent $t$ test. Dependent $t$ test merupakan uji komparatif rerata produktivitas yang dilakukan pada satu sampel berpasangan. Rumus dependent $t$ test untuk pengujian sebagai berikut:

$$
\begin{gathered}
t=\frac{M D}{\sqrt{\frac{\sum d^{2}}{N(N-1)}}} \\
M D=\frac{\sum D}{N}
\end{gathered}
$$

Keterangan :

$\mathrm{MD}=$ Rerata perbedaan

$\sum d^{2}=$ Jumlah kuadrat dari perbedaan deviasi mean

$\mathrm{N}=$ Jumlah pasangan atau subjek

$\mu 1=$ Produktivitas tanaman kakao umur $<15$ tahun

$\mu 2=$ Produktivitas tanaman kakao umur $\geq 15$ tahun

\section{HASIL DAN PEMBAHASAN}

\section{Budidaya Kakao Petani Taman Teknologi Pertanian Nglanggeran}

Salah satu komoditas perkebunan yang cukup besar di Indonesia adalah kakao akan tetapi produksi buah ini belum optimal. Hal tersebut dipengaruhi oleh banyak faktor seperti pemeliharaan kakao yang kurang tepat dan sistem budidaya kakao yang belum sesuai. Kesalahan teknis seperti hal tersebut akan menyebabkan kerugian dalam budidaya kakao.

TTP Nglanggeran adalah salah satu Taman Teknologi Pertanian yang dibangun untuk suatu kawasan implementasi inovasi berskala pengembangan, berwawasan agribisnis hulu-hilir, bersifat spesifik lokasi, kegiatannya meliputi penerapan teknologi, pelatihan dan pembelajaran bagi masyarakat serta pengembangan kemitraan agribisnis dengan swasta. Petani di Desa Nglanggeran yang tergabung ke dalam Taman Teknologi Pertanian memang profesi utamanya adalah petani kakao serta peternak kambing etawa dimana di Taman Teknologi Pertanian Nglanggeran mengintegrasi keduanya. Terdapat beberapa penyuluh yang turun langsung dan mendampingi petani kakao dalam menangai budidaya kakao. Taman Teknologi Pertanian juga memiliki program untuk petani kakao di Desa Nglanggeran seperti menampung panenan dari petani baik panenan dalam bentuk kakao segar maupun yang sudah terfermentasi. Harga yang diberikan juga termasuk harga wajar dan mementingkan kesejahteraan petani. Usahatani kakao pada dasarnya dipengaruhi oleh faktor fisik dan non fisik seperti segi kesesuaian lahan (air, aerasi dan drainase). Jika ditinjau dari segi kesesuaian lahan daerah Nglanggeran sangat cocok untuk dibudidayakan kakao. Modal juga merupakan faktor penting dalam budidaya kakao. Hal tersebut diwujudkan dalam kepemilikan lahan dan jumlah kakao yang tersedia dan tertanam di 
lahan tersebut. Hubungan luas lahan dan jumlah pohon kakao dapat dilihat pada tabel 1 sebagai berikut :

Tabel 1. Luas Kepemilikan Lahan Petani dengan Jumlah Pohon Kakao

\begin{tabular}{|c|c|c|c|}
\hline \multirow{2}{*}{ Luas lahan } & \multirow[t]{2}{*}{ Jumlah pohon kakao } & $<250$ & \multirow[t]{2}{*}{$>250$} \\
\hline & & Persentase $(\%)$ & \\
\hline$<1000$ & & 3.33 & 0.00 \\
\hline $1000-3000$ & & 53.33 & 0.00 \\
\hline $3001-5000$ & & 13.33 & 3.33 \\
\hline $5001-7000$ & & 3.33 & 3.33 \\
\hline 7001-9000 & & 6.66 & 6.66 \\
\hline$>10000$ & & 3.33 & 3.33 \\
\hline Jumlah & & 83,31 & 16,69 \\
\hline
\end{tabular}

Sumber: Analisis Data Primer, 2020

Berdasarkan tabel 1 dapat diketahui bahwa kepemilikan luas lahan dengan jumlah pohon kakao miliki petani Nglanggeran sebagian besar memiliki luasan $1000 \mathrm{~m}^{2}$ hingga $3000 \mathrm{~m}^{2}$. Sebanyak $23,33 \%$ petani memiliki luasan lahan yang cukup luas sekitar $3000 \mathrm{~m}^{2}$ hingga 9000 $\mathrm{m}^{2}$. Masih ada petani yang memiliki luasan kurang dari $1000 \mathrm{~m}^{2}$ dan terdapat pula petani sebanyak $3,33 \%$ yang memiliki luasan lebih dari 1 Ha. Lahan yang diperuntukkan budidaya kakao sebagian besar berupa tegalan dan pekarangan. Melihat jumlah pohon yang ditanam jika dibandingkan dengan luasan lahan yang dimiliki memang belum efektif. Kebanyakan petani menanam pohon kurang dari 250 pohon di setiap areal luasan yang dimiliki. Hal tersebut juga akan mempengaruhi produksi yang dihasilkan. Jika dilihat dari perbandingan luas dengan populasi kakao masih belum seimbang dan masih bisa di tingkatkan. Jarak tanam ideal untuk tanaman kakao terbagi menjadi dua yaitu dengan jarak tanam $2 \times 4$ dengan populasi 1.250/ha atau $3 \times 3$ populasi perhektar 1.100 pohon.

\section{Gross Margin Usahatani Tanaman Kakao Per Hektar Usia Produktif}

Rumah tangga tani di Desa Nglanggeran bersumber dari usaha tani kakao. Perhitungan mengenai gross margin kakao terkait dengan tanaman kakao yang dibudidayakan. Perhitungan gross margin dihitung dengan mencari penerimaan petani dari kakao kemudian diselisihkan dengan total biaya variabel meliputi biaya tenaga kerja, sarana alat produksi, penyusutan alat dan biaya lainnya. Tenaga kerja yang dimaksud adalah biaya tenaga kerja dalam keluarga dan tenaga kerja luar keluarga. Sarana alat produksi yang dimaksud merupakan keseluruhan sarana dan alat produksi yang digunakan dalam membudidayakan kakao seperti pupuk dan pestisida. Alat-alat pertanian yang digunakan dalam berbudidaya kakao seperti gunting pangkas, gunting tali panjang, cangkul, 
sabit, pecok dan lainnya. Biaya lain-lain yang dimaksud meliputi pajak lahan. Gross margin rata-rata usahatani kakao di Desa
Nglanggeran dapat dilihat pada tabel 2 dan 3.

Tabel 2. Gross Margin Rata-Rata Usahatani Tanaman Kakao Umur Produktif

\begin{tabular}{lr}
\hline Keterangan & Nilai (Rp) \\
\hline Nilai produksi (A) & 6.697 .840 \\
Biaya-biaya (B) & \\
Tenaga kerja & 385.000 \\
Saprodi & 339.578 \\
Penyusutan alat & 278.000 \\
$\quad$ Lain-lain & 45.000 \\
\hline Total biaya variabel & 1.047 .578 \\
\hline Gross Margin (A-B) & 5.650 .262 \\
\hline
\end{tabular}

Sumber : Analisis Data Primer, 2020

Berdasarkan tabel 2 dapat diketahui bahwa penerimaan petani kakao yang memiliki kakao usia produktif sebesar Rp 6.697.840 dan menerima gross margin sebesar Rp 5.650.262. Total biaya variabel yang dikeluarkan untuk berbudidaya kakao berjumlah $\mathrm{Rp}$ 1.047.578. Nilai biaya tersebut meliputi tenaga kerja, sarana alat produksi, penyusutan alat dan biaya lainnya. Tenaga kerja yang dibutuhkan merupakan tenaga kerja dalam keluarga dan tenaga kerja luar keluarga. Sarana alat produksi yang dikeluarkan sebesar $\mathrm{Rp}$ 339.578 meliputi salah satunya biaya pembelian pupuk dan pembelian pestisida. Penyusutan alat merupakan alat yang digunakan petani dalam berbudidaya termasuk alat-alat panen seperti gunting pangkas dan gunting tali panjang.

Tabel 3. Gross Margin Rata-Rata Usahatani Tanaman Kakao Umur Tidak Produktif

\begin{tabular}{lr}
\hline Keterangan & Nilai (Rp) \\
\hline Nilai produksi (A) & 5.295 .667 \\
Biaya-biaya (B) & 320.000 \\
Tenaga kerja & 347.115 \\
Saprodi & 296.000 \\
Penyusutan alat & 35.000 \\
$\quad$ Lain-lain & 998.115 \\
\hline Total biaya variabel & 4.297 .552 \\
\hline Gross Margin (A-B)
\end{tabular}

Sumber : Analisis Data Primer, 2020

Nilai produksi tanaman kakao umur tidak produktif adalah sebesar $\mathrm{Rp}$ 5.295.667. Komponen biaya produksi yang dikeluarkan untuk tenaga kerja adalah sebesar Rp 320.000. Biaya saprodi yang dikeluarkan adalah sebesar Rp 347.115.
Untuk biaya penyusutan yang dikeluarkan adalah sebesar Rp 296.000 dan untuk biaya lain-lain yang dikeluarkan adalah sebesar $\mathrm{Rp}$ 35.100. Total biaya variabel yang dikeluarkan adalah sebesar Rp 998.115. Gross Margin petani dari usahatani kakao 
yang dihasilkan adalah sebesar $\mathrm{Rp}$ 4.297.552. Hasil ini tidak cukup besar karena sering adanya hama dan penyakit pada tanaman kakao, dikarenakan kakao yang memasuki umur tidak produktif biasanya rentan terhadap serangan hama dan penyakit tanaman serta memang hasil produksi petani yang kurang optimal. Jika dilihat dari hasil yang ada kakao dengan umur produktif memberikan hasil yang lebih baik dengan penerimaan dan gross margin yang lebih tinggi dibandingkan kakao yang masuk ke dalam umur tidak produktif. Terdapat selisih sebanyak $\mathrm{Rp}$ 1.402.173 dalam nilai produksi tanaman kakao dan terdapat selisih sebesar $\mathrm{Rp}$ 1.352.710 dalam nilai gross margin masing masing usia tanaman kakao.

\section{Uji T-Test Paired Two Sample}

Tabel 4. Dependent t Test Produktivitas Kakao di Taman Teknologi Pertanian Nglanggeran

\begin{tabular}{|c|c|c|}
\hline & Umur $<15$ tahun & $\begin{array}{l}\text { Umur } \geq 15 \\
\text { tahun }\end{array}$ \\
\hline Rerata Produktivitas & 744,20 & 588,41 \\
\hline $\mathrm{N}$ & 15 & 15 \\
\hline$t_{\text {hitung }}$ & & \\
\hline$t_{\text {tabel }}$ & & \\
\hline Sig-t & & \\
\hline
\end{tabular}

Sumber : Analisis Data Primer, 2020

Berdasarkan tabel 4 mengenai uji dependen t-test dapat diketahui bahwa produktivitas kakao umur kurang 15 tahun sebesar 744,20 $\mathrm{Kg} / \mathrm{Ha}$ sedangkan produktivitas kakao lebih dari sama dengan 15 tahun sebesar 588,41 Kg/Ha. Hasil uji dependent $t$ test menunjukkan bahwa Ho ditolak (sig-t $<0,05$ ) berarti produktivitas tanaman kakao umur kurang dari 15 tahun lebih besar dibandingkan dengan produktivitas kakao umur di atas atau sama dengan 15 tahun dengan tingkat kesalahan $5 \%$. Kondisi ini dikarenakan produktivitas kakao yang berumur lebih dari 15 tahun sudah mengalami penurunan produktivitas dengan kata lain produktivitasnya sudah tidak maksimal. Selain itu karena tanaman kakao yang berumur lebih dari 15 tahun sudah memasuki usia tidak produktif sehingga perlu adanya peremajaan kembali agar dapat mempertahankan produktivitas kakao. Beberapa cara dapat dilakukan sebagai upaya rehabilitasi tanaman kakao. satunya dilakukan dengan teknologi sambung samping (Tjahjana dan Sobari, 2014). Hal tersebut perlu dilakukan sebagai upaya perbaikan maupun peningkatan produktivitas tanaman kakao yang sudah masuk ke dalam usia tidak produktif.

\section{KESIMPULAN}

Berdasarkan hasil penelitian mengenai produktivitas tanaman kakao umur produktif jika dibandingkan dengan kakao umur tidak produktif diperoleh hasil bahwa rerata kakao yang memiliki umur produktif kurang dari 15 tahun memiliki produktivitas $744,20 \mathrm{Kg} / \mathrm{Ha}$. Kakao yang memiliki umur tidak produktif lebih dari sama dengan lima belas tahun memiliki produktivitas 588,41. Dengan begitu dapat disimpulkan bahwa kakao yang memiliki 
produktivitas yang baik adalah kakao yang memiliki umur kurang dari 15 tahun. Sebaiknya petani meregenerasi tanaman kakao yang sudah tidak produktif dengan tanaman baru. Upaya rehabilitasi tanaman kakao untuk memperbaiki atau meningkatkan potensi produktivitas dan salah satunya juga bisa dilakukan dengan penggunakan inovasi teknologi berupa teknologi sambung samping.

\section{DAFTAR PUSTAKA}

Alkamalia, I., Mawardati, M., \& Budi, S. (2017). Analisis Pengaruh Luas Lahan Dan Tenaga Kerja Terhadap Produksi Kakao Perkebunan Rakyat Di Provinsi Aceh. Agrifo: Jurnal Agribisnis Universitas Malikussaleh, 2(2), 56-61.

Apriliawan, A., Manumono, D., \& Suswatiningsih, T. E. (2018). STRATEGI PENGEMBANGAN USAHATANI KAKAO DI DESA BANJAROYO KECAMATAN KALIBAWANG KABUPATEN KULONPROGO. JURNAL MASEPI, 3(1).

Ebewore, S. O., Egho, E. O., \& Enujeke, E. C. (2013). Effect of farmer field school training on the management of cocoa marids (Saghbergella singularis) by famers in edo state Nigeria. Asian Journal of Agricultural Sciences, 5(1), 6-10.

Ikhsan, I., Arida, A., \& Fauzi, T. (2016). Faktor-Faktor Yang Mempengaruhi Produktivitas Kakao Pada Perkebunan Rakyat Di Kabupaten Pidie Jaya. Jurnal Ilmiah Mahasiswa
Pertanian, 1(1), 321-328.

Oyediran, W. O., Omoare, A. M., Ajagbe, B. O., \& Sofowora, O. O. (2014). Attitude of cocoa farmers to growth enhancement support scheme (GES) in Ijebu east local government area of Ogun State, Nigeria. World Journal of Biology and Medical Sciences, 1(3), 108-117.

Saleh, A. R., \& Jayanti, K. D. (2017). Pengaruh Populasi Naungan terhadap Pertumbuhan Awal Tanaman Kakao (Theobroma cocoa L.) di Lapangan. Agropet, 14(2).

Saputro, W. A., \& Fidayani, Y. (2020). FAKTOR-FAKTOR YANG MEMPENGARUHI PRODUKSI KAKAO DESA NGLANGGERAN KECAMATAN PATUK KABUPATEN GUNUNGKIDUL. VIGOR: JURNAL ILMU PERTANIAN TROPIKA DAN SUBTROPIKA (JOURNAL OF TROPICAL AND SUBTROPICAL AGRICULTURAL SCIENCES), 5(1), 24-30.

Saputro, W. A., \& Sariningsih, W. (2020). KONTRIBUSI PENDAPATAN USAHATANI KAKAO TERHADAP PENDAPATAN RUMAH TANGGA PETANI DI TAMAN TEKNOLOGI PERTANIAN NGLANGGERAN KECAMATAN PATHUK KABUPATEN GUNUNGKIDUL. SEPA: Jurnal Sosial Ekonomi Pertanian Dan Agribisnis, 16(2), 208-217. 
Sugiyono, M. (2013). Kualitatif, dan Kombinasi (Mixed Methods). Bandung: Alfabeta.

Tjahjana, B. E., \& Sobari, I. (2014). Rehabilitasi kakao rakyat dengaan sambung samping. Sirinov, 2(1), 2534.

Zainudin, \& Baon, J. B. (2004). Prospek kakao nasional, Satu Dasa Warsa (2005-2014) mendatang antisipasi pengembangan kakao nasional menghadapi regenerasi pertama kakao di Indonesia. Prosiding Simposium Kakao 2004. Yogyakarta: Pusat Penelitian kopi dan kakao Indonesia. 